\title{
Neuropsychological aspects of Asperger Syndrome in adults: a review
}

\section{Stefania Brighenti ${ }^{1}$ - Selene Schintu ${ }^{2}$ - Donato Liloia ${ }^{3}$ Roberto Keller ${ }^{1}$}

${ }^{1}$ Centre for Autism Spectrum Disorder in Adulthood DSM ASL City of Turin, Turin, Italy

${ }^{2}$ Department of Psychology, George Washington University, DC, Washington, USA

${ }^{2}$ FOCUS Lab, Department of Psychology, University of Turin, Turin, Italy

\section{ABSTRACT}

Despite distinctive clinical characteristics, Asperger Syndrome (AS) is actually included in the broad spectrum of Autism Spectrum Disorder. Usually, to evaluate AS in adulthood, diagnostic tools are referred to autistic traits; furthermore, $A S^{\prime}$ neuropsychological profile features are still unclear. The aim of the present review is to shed light on the cognitive characteristics of adults with AS. Limited number of studies have investigated the neuropsychological profile of adults with AS: individuals with AS have intellectual abilities in the normal range and show strengths in verbal memory, inhibitory control and decision making. Disagreement exists about the presence of deficits in attentional functions, visual-spatial memory, cognitive flexibility, planning and verbal fluency.

The present work underlines the need for a neuropsychological assessment in order to delineate the cognitive profile of adults with AS, which could help in the diagnosis of AS in adulthood and to design rehabilitative protocols.

Keywords: Asperger syndrome; autism; pervasive developmental disorders; cognitive profile; neuropsychology 


\section{INTRODUCTION}

The appearance of Autism and Asperger Syndrome (AS) was marked by an interesting coincidence (Barahona-Correa \& Filipe, 2015): both Kanner (1943) and Asperger (1944) took the term "autism" from the Bleuler's (1911) description of schizophrenia. In contrast to schizophrenia, however, this syndrome manifests in early childhood and social interaction may improve with growth. Kanner (1943) described the crucial features of the disorder as both extreme self-isolation and obsessive insistence on sameness, accompanied, however, by good cognitive potential. On the other hand, Asperger (1944) focused his description on verbal, linguistic and cognitive abilities that seemed to be excellent despite the presence of deficits in social skills. Asperger (1944) emphasized positive features (e.g. extremely original thoughts, abstract or intellectualized interest) concluding that his patients were clearly different from those described by Kanner (1943) by the fact that those with Asperger Syndrome had good cognitive and linguistic skills and normal development in the first 2-3 years of life.

These two descriptions, despite stemming from the same source, seem to depict two different conditions that could nowadays be identified respectively as "Autism" and "Asperger Syndrome".

Kanner's syndrome was included in DSM-III (American Psychiatric Association, 1980) which was published in 1980, whereas Asperger's work remained virtually unknown until Lorna Wing (1981) and Uta Frith (1991) mentioned it in their publications. This delay may explain why Asperger Syndrome in adulthood was often undetected or misdiagnosed by clinicians in the past years (Keller, Piedimonte, Bianco, Bari, \& Cauda, 2016; Luciano et al., 2014).

Lorna Wing (1981) described AS as characterized by social isolation, lack of reciprocity in social interactions, normal or precocious language acquisition, aboveaverage linguistic skills but subtle abnormalities of verbal and non-verbal communication, narrow focus of interest, overachievement in specific cognitive domains and motor clumsiness.

The distinction between these two conditions became formal in the 90s with the publication of the DSM IV (American Psychiatric Association, 1994). However, this distinction was short lived and, indeed, it is not anymore reported in the last and fifth edition of the DSM (American Psychiatric Association, 2013). In the DSM 5 Asperger Syndrome has been included in the Autism Spectrum Disorder (ASD; level 1). In detail, ASD is characterized by a first criterion which consist of persistent deficits in social communication and interaction across contexts and manifested by deficits in social-emotional reciprocity in nonverbal communicative behaviours used for social interaction and in developing and maintaining relationships. The second criterion includes the presence of restricted, repetitive patterns of behaviour, interests or activities manifested as 
at least two of the following ones: 1) stereotyped or repetitive speech, motor movements or use of objects; 2) excessive adherence to routines, ritualized patterns of verbal or nonverbal behaviour or excessive resistance to change; 3 ) highly restricted, fixated interests that are abnormal in intensity or focus; 4) hyper- or hypo-reactivity to sensory inputs or unusual interest in sensory aspects of environment. All these symptoms must be present in early childhood but may not become fully manifest until social demands exceed limited capacities and together limit and impair everyday functioning.

The DSM 5 defines ASD as a cluster of disorders (Krystal \& State, 2014) but with a common clinical observation that autism includes subtypes of disorders with large differences in functioning that could be caused by different neurobiological bases (genetic syndrome or not, autism with severe intellectual disability and language disorder or high academic performance) (Biamino et al., 2016; Di Gregorio et al., 2017).

ASD broad spectrum can be useful as a general conceptualization of autism, but in clinical practice patients with AS are substantially different from ASD patients who have intellectual disability and therefore require different treatment. Adults with AS are close to neurotypical people (NT, i.e., individuals who are not on the autism spectrum) and it is therefore necessary to detect neuropsychological aspects and clinical symptoms that could help clinicians to clear cut the syndrome from general population and from ASD.

Compared to High Functioning Autism (HF), AS presents a richer verbal knowledge, more sophisticate special interests and less bizarre behavior. That is a reason why patients with AS are less often diagnosed and treated since early childhood then patient with ASD: this delay in diagnosis and treatments contributes to the presence of psychopathological comorbidity (such as depressive disorder, anxiety and psychosis) (Keller et al., 2015).

It may therefore be useful to maintain AS a distinct syndrome in clinical practice, in order to delineate AS neuropsychological profile, psychopathological comorbidities (Keller et al., 2016) and treatment options.

\subsection{A Theoretical Account}

Although several theories concerning Autism Spectrum Disorder have been proposed, specific theories accounting for Asperger Syndrome are lacking so far.

A deficit of Theory of Mind. Most experimental and clinical evidence show that most autistic behaviours, in particular those related to communication and social interaction, are due to a deficit of the theory of mind. This theory suggests that autistic individuals have deficits in mentalizing, perceiving and interpreting intentional mental states of others (e.g., intentions, 
beliefs, expectations, needs, desires, feelings, goals, purposes, and reasons) or using this knowledge to understand the mechanisms of communication and building relationships (Baron-Cohen et al., 1994; Baron-Cohen, Leslie, \& Frith, 1985; Fonagy \& Target, 1997; Frith \& Frith, 1999; Hadwin, BaronCohen, Howlin, \& Hill, 1997; Holroyd \& Baron-Cohen, 1993; Premack \& Woodruff, 1978). A deficit of theory of mind can account for impaired social behaviour in Autism Spectrum Disorders, as in Asperger Syndrome, but fails to explain the restricted interests.

The "broken" mirror neuron theory. More recently, a different perspective of autistic disorder has been proposed by the "broken" mirror neuron theory. This theory postulates that individuals with autism have deficits in embodying others' mental states and thus show difficulties with imitation, understanding intention in others' actions or recognizing emotion in others' expressions due to hypoactivation of the mirror neuron system (e.g., frontal and parietal cortex and amygdala) (Keller, Bugiani, Fantin, \& Pirfo, 2011; Rizzolatti \& Fabbri-Destro, 2010; Saffin \& Tohid, 2016). The mirror neuron system is a network of neurons that fires when a person performs an action or observes someone else performing the same action (for a review see Rizzolatti \& Craighero, 2004; Rizzolatti, Fadiga, Gallese, \& Fogassi, 1996). It allows individuals to experience the mental states of others as if they were one's own (Keller et al., 2011). The correlation between reduced grey matter thickness of this system in autistic patients with deficits in communication and social interaction (for a meta-analysis see Cauda et al., 2011; Cauda et al., 2014) supports the idea of the mirror neuron system being fundamental for social interaction. This theory can therefore explain peculiar behaviours in social interactions in Asperger Syndrome, communicative deficits and difficulties in understanding other's intentions and the functional meaning of other's actions.

The extreme male brain. A third possible theoretical frame defines ASD symptoms as the expression of the extreme male brain (Baron-Cohen, 2002). The cognitive profile of the autistic brain would be attributed to an extreme ability in systematization due to scarce empathy. The autistic mind would be the extreme manifestation of what is coarsely called the "male brain": ASD is more commonly diagnosed in males than females which offers supports to this theory (Baron-Cohen et al., 2011). This theory would account for systemizing tendencies and the restricted interests showed by individuals with AS.

The weak central coherence theory. The weak central coherence theory (Frith, 1989; Happé, 1999) underlines the difficulties of autistic individuals in elaborating the global aspect of stimuli, their tendency to be captured by details 
and the difficulty of synthesis of information coming from different sensory modalities to create a global representation. However, this particular level of information processing has also been considered a cognitive style and not a deficit per se and could explain autistic talents (Boso et al., 2010; Happé, 1999). Enhanced ability in perceptive discrimination may be the result of enhanced perception and may account for both the exceptional intellectual abilities and the variability in the spectrum (Mottron et al., 2013; Mottron, Dawson, Soulieres, Hubert, \& Burack, 2006). This theory would account for similar characteristics exhibited by individuals with AS such as restricted interests and predisposition to focus on details.

Executive dysfunction theory. The executive dysfunction theory proposes that deficits in the frontal and prefrontal cerebral circuits are responsible for the repetitive and stereotyped behaviours, restricted interests and difficulties in communicating and socializing that are typical in individuals with ASD (Hill, 2004; Hill \& Bird, 2006; Ozonoff \& Jensen, 1999; Russell, 1997). This theory may help us understand AS' restricted and intense interests, necessity of daily routine and predictability. Furthermore, failures in social interactions and communications, typical of AS, can be explained by deficits in the executive functions system.

The right hemisphere dysfunction theory. The right hemisphere dysfunction theory (Klin, Volkmar, Sparrow, Cicchetti, \& Rourke, 1995) proposes that Asperger Syndrome, similar to Nonverbal Learning Disability (NVLD), can be due to an understimulation or a dysfunction in communication of the right hemisphere (Williams, Goldstein, Kojkowski, \& Minshew, 2008). Myklebust (1975) and Rourke (1987, 1988, 1995) first described NVLD as diagnosed on deficits in nonverbal problem solving, visualspatial organization, tactile perception and psychomotor coordination (Gunter, Ghaziuddin, \& Ellis, 2002). Sometimes, difficulties in some aspects of pragmatic communication and prosody, social judgment and reasoning and social interaction are also present. However, these deficits are accompanied by verbal memory abilities that are sometimes above average. (For a full and recent review see Fine, Semrud-Clikeman, Bledsoe, \& Musielak, 2013).

Both AS and NVLD individuals have preserved linguistic abilities but have deficits in visual-spatial abilities as well as executive functions despite preservation of their linguistic abilities (Klin et al., 1995) without sharing other symptoms typical of ASD such as special interests or sensory hyper-sensibility.

The profile exhibited by patients with right hemisphere dysfunction has been described as being similar to AS. The hemispheric specialization theory (visual-spatial analyses is sub-served by the right hemisphere and primary 
language functions by the left), contrary to other theoretical accounts, could hence explain the discrepancy between the performance obtained by individuals with AS in verbal (good performance) and visual-spatial tasks (poor performance) tasks. This theory also accounts for their failures in social and pragmatic aspects of language which are commonly ascribed to the right hemisphere (Moseley et al., 2016). However, the right hemisphere dysfunction theory fails explain selective and special interest in AS.

Despite these and other theoretical models' attempts, to date, no theory has been able to provide a unique explanation or cause for the complex behavioural and cognitive symptoms of ASD (Wilson et al., 2014). This absence of a convergent model accounting for both ASD and AS neuropsychological profile supports the independence of these two syndromes.

\subsection{Clinical Evaluation}

Autism Spectrum Disorders include a range of neurodevelopmental deficits that persist for the whole life. Thus, specific and early treatments are crucial and should be protracted into adulthood (Luciano et al., 2014). If we consider autism as a spectrum, tests and questionnaires usually employed for ASD diagnosis in adults are frequently misused for the diagnosis of AS (Keller et al., 2015; Luciano et al., 2014). Among those worthwhile mentioning are the Empathy Quotient (EQ) (Baron-Cohen \& Wheelwright, 2004), the Autism Quotient (AQ) (Baron-Cohen, Wheelwright, Skinner, Martin, \& Clubley, 2001), Autism Diagnostic Interview (ADI-r) (Rutter, Le Couteur, \& Lord, 2003) and the Autism Diagnostic Observation Schedule 4th module (ADOS) (Lord, Rutter, DiLavore, \& Risi, 2008). Both AQ and EQ are useful research tools. However, they are self-report questionnaires and hence are limited in identifying patients with AS if the patients are unaware of their symptoms. The ADOS may not be sensitive enough to distinguish ASD from psychosis in adulthood (Keller et al., 2016) and is too simplistic and therefore not suited for individuals with high Intelligence Quotient (AS). ADI-r, administered in childhood, could return false negatives because AS symptoms may be exhibited later in life compared to the typical ASD symptoms.

Even if diagnostic tools specific for Asperger Syndrome in adulthood, such as the Gilliam's Asperger Disorders Scale (GADS) (Gilliam, 2001), the Adult Asperger Assessment (Baron-Cohen, Wheelwright, Robinson, \& Woodbury-Smith, 2005) and the Ritvo Autism Asperger Diagnostic Scale Revised (RAADS-R) (Ritvo et al., 2011) are more sensitive in diagnosis, they are not exhaustive in describing the cognitive and neuropsychological profiles 
of adults with AS. These individuals can receive their first correct diagnosis in adulthood after being earlier misdiagnosed as affected by personality disorders (e.g., borderline personality disorder or obsessive compulsive disorder), schizophrenia (or other psychotic disorders) or other psychiatric conditions (e.g., emotional and/or behavioural disorders, social phobia and anxiety, and depressive disorders) (Keller et al., 2015; Keller et al., 2016; Luciano et al., 2014; Morris et al., 1999; Noterdaeme, Wriedt, \& Höhne, 2010). A cause for the misdiagnosis may be the delay of scientific knowledge of AS (as described above). Another problem may be related to high academic performance of individuals with Asperger Syndrome that drive parents and teachers to consider bizarre behaviour or social deficit as a "side effect" of a child's genius: a potential reason why it may not be considered a disorder during childhood.

The clinical features of this disorder in adulthood may be different than in childhood; it is therefore possible that individuals with AS develop compensatory mechanisms as they age mitigating their deficits. A further level of complexity added to the already tangled clinical diagnosis of AS in adults is given by "camouflaging", especially in women (Lai \& Baron-Cohen, 2015). Also, AS symptoms could be hidden by psychiatric comorbidity linked to stress related to lack of diagnosis (Lai \& Baron-Cohen, 2015).

From a clinical point of view, it is therefore necessary to use sensitive and specific diagnostic tools to ultimately offer patients the appropriate rehabilitative programme.

\section{METHOD}

In the present systematic review, we aim to analyse literature concerning neuropsychological aspects of asperger syndrome in adults in order to delineate its cognitive characteristics.

\subsection{Selection of studies}

To ensure a transparent description of the selection process, we followed the "prisma statement" international guidelines (Liberati et al., 2009; Moher, Liberati, Tetzlaff, \& Altman, 2009). the medline database with pubmed literature search (http://www.ncbi.nlm.nih.gov/pubmed) was employed in the search of studies published until june 2017.

In particular, we have adopted the mesh hierarchy for mental disorders in pubmed routines to find published articles of interest: we provided a set of keywords as input, adopting boolean operators and pubmed search field tags. 
specifically, for this study the search algorithm was defined as follows:

- asperger adults and (memory or attention or neuropsychology or executive functions or cognitive evaluation or cognitive functions or praxis)

Our search strategy found a total of 347 articles in pubmed database. five additional records were identified through other sources. any article not meeting specific inclusion criteria was excluded. in particular, an expert researcher reviewed all the full-text articles independently in order to ensure: 1 ) the presence of studies about subjects with diagnosis of asperger syndrome in adulthood with neurotypical controls, asd or hf (high-functioning autism) control groups; 2) that previously-validated neuropsychological testing instruments were used; 3) that the studies were written in english.

We excluded 1) articles focused on theory of mind, empathy or emotional processing because we focused our research on neuropsychological functioning of as solely; 2) studies that used neuroimaging approaches 3) studies with samples composed by high functioning or autism adults; 3) studies about children and adolescents; 4) papers about the validation of assessment tools; 5) papers analysed the clinical outcomes 6) studies concerning other medical or clinical conditions, 7) papers not written in english (see figure 1- prisma flow chart for a detailed overview of the selection strategy).

Based on the aforementioned criteria, 19 papers were included in the systematic review, for a total of 23 experiments, one review and 573 subjects with asperger syndrome. relevant descriptive information was extracted from each full-text article. the detailed description of the sample and results in neuropsychological tests of the selected papers can be viewed in the table 1 and table 2. 


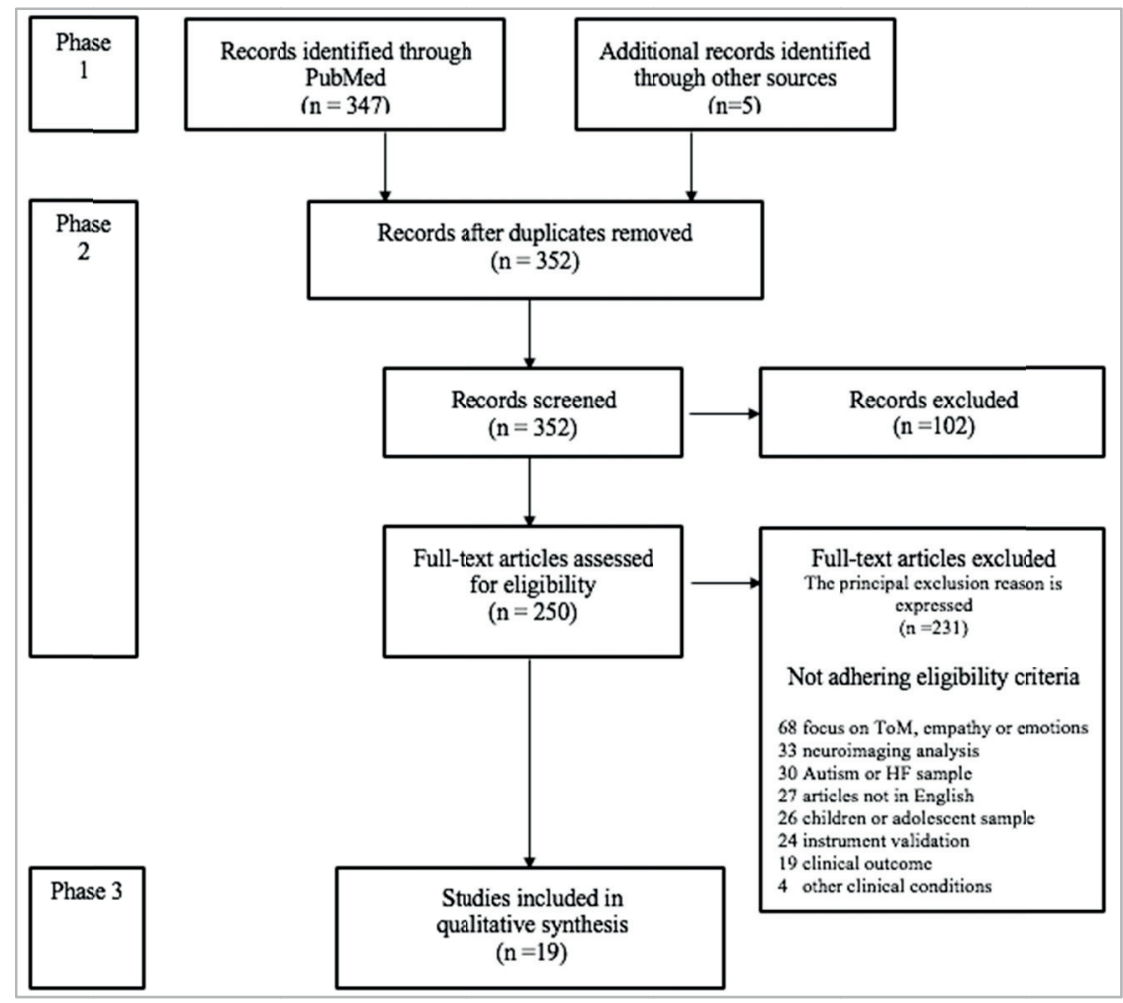

Figure 1. PRISMA Flow Chart. Overview of the selection strategy

\section{RESULTS}

A limited number of studies have investigated the neuropsychological profile of adults with AS (See Table 1): the results achieved by the authors are contradictory to each other but interesting findings emerged (See Table 2).

\subsection{Intellectual performance}

The intellectual performance of individuals with AS is overall comparable to the neurotypical's ones (control group). However, the cognitive profiling in AS is limited. Only few studies have evaluated adults with Asperger Syndrome 
(Ambery, Russell, Perry, Morris, \& Murphy, 2006; Cederlund, Hagberg, \& Gillberg, 2010; Holdnack, Goldstein, \& Drozdick, 2011; Spek, Scholte, \& van Berckelaer-Onnes, 2008; Wilson et al., 2014).

Wechsler Adult Intelligence Scales (WAIS-R; WAIS III) (Wechsler, 1981; Wechsler, 1997) are the most common tools utilized to evaluate intelligence in adults. Beside Full Scale Intelligence Quotient (FSIQ), WAIS scales provide two Quotients (until the last version): the Performance Intelligence Quotient (PIQ) and the Verbal Intelligence Quotient (VIQ). The first one is an index of visual-spatial abilities and fluid intelligence; the second one is an index of verbal reasoning, verbal abilities and crystallized intelligence. AS Verbal IQ scores are generally higher than their Performance ones (Gunter et al., 2002; Hagberg, Billstedt, Nydén, \& Gillberg, 2015; Hagberg, Nydén, Cederlund, \& Gillberg, 2013), although not every author obtained the same results (Spek et al., 2008).

On Canavan, Dunn, and Mcmillan (1986) short form of WAIS-R, Ambery and colleagues (2006) didn't find differences between AS and controls on general intelligence functioning. Hagberg and colleagues (2013), found that Nonverbal Learning Disability (defined as NVLD =VIQ > PIQ $\geq 15$ points) was present in 15 out of 69 adults with AS. Moreover, adults with AS show higher score on Full Scale IQ than other ASD (Cederlund et al., 2010). Comparing High-Functioning Autism to Asperger Syndrome, Kleinhans, Akshoomoff and Delis (2005) failed to detect differences between AS and HF on the Wechsler Abbreviated Scale of Intelligence (WASI; Wechsler, 1999).

The fourth and last version of WAIS (WAIS IV; Wechsler, 2008) underwent changes: beside Intelligence Quotient and General Ability Index, WAIS IV allows to calculate 4 further indices (Holdnack et al., 2011). The Verbal Comprehension Index (VCI -an index of verbal abilities, verbal and logic reasoning), the Perceptive Reasoning Index (PRI - an index of visualmotor coordination, visual and non-verbal reasoning); the Working Memory Index (WMI - and index of working memory, short term auditory and verbal memory and calculation capability) and Processing Speed Index (PSI- a measure of selective attention, visual-spatial exploration, executive speed). Holdnack and colleagues (2011) found that, on WAIS IV, AS group's Full Scale IQ is comparable to NT and higher than High-Functioning Autism. In addition, AS group's Verbal Comprehension Index, Perceptual Reasoning Index and Working Memory Index do not differ from the control group; moreover, NT obtain higher Processing Speed Index score than AS and HF. Finally, AS performance on Processing Speed Index subtests is better than HF.

Taken together, these cognitive differences between individuals with AS and HF may support the existence of subgroups within autism spectrum conditions.

As previously shown, a large number of studies have underlined the 
cognitive difference between High-Functioning autism and AS (Morris et al., 1999; Noterdaeme et al., 2010). Among those authors, Mottron et al. (2013) propose a distinction between those individuals based on the presence (HF) or absence (AS) of a delay in language acquisition. Individuals with HF would show good visual-spatial reasoning skills but deficits in linguistic abilities, whereas individuals with AS would show deficits in visual-motor skills and coordination, but not delays in language acquisition. The use of other tests such as Raven Progressive Matrices (Raven, 1941) has given intriguing results. Raven's Progressive Matrices is mainly used to evaluate fluid intelligence and visual-spatial reasoning abilities. Asperger individuals obtain better scores on the Raven Matrices, compared to WAIS-III Full Scale and Performance IQ scores (Soulières, Dawson, Gernsbacher, \& Mottron, 2011). Considering this, the difficulties observed on the WAIS Performance subtests -which predicts deficits in visual-spatial reasoning- can be actually due to the use of an evaluation tool that is only partially appropriate in gathering the variability of autistic intelligence (Hayashi, Kato, Igarashi, \& Kashima, 2008; Soulières et al., 2011). However, it has been suggested that Raven Matrices and WAIS scales bring unique contributions in establishing a baseline cognitive profile in such ASD populations (Bodner, Williams, Engelhardt, \& Minshew, 2014).

\subsection{Attentional Functions and Perceptual Abilities}

Attentional abilities and shifting. Only few studies have evaluated attention abilities in Asperger Syndrome (Hill \& Bird, 2006; Towgood, Meuwese, Gilbert, Turner \& Burgess 2009; Kleinhans et al., 2005; Torralva et al., 2013).

AS attentional and visual scanning abilities seem to be better than the High-Functioning autism individuals (Kleinhans et al., 2005): both on Processing Speed factor scale (WAIS-III) and Processing Speed Index score (WAIS IV) patients with AS show to be faster than HF (Spek, Scholte, \& van Berckelaer-Onnes, 2011; Holdnack et al., 2011).

The most common neuropsychological tool employed to assess attentive functions, visual scanning and cognitive speed (Tombaugh, 2004) is Trail Making Test (TMT) (Reitan, 1958). TMT is composed of 2 parts (Tombaugh, 2004): the first part (TMT A) provides a measure of visual-spatial exploration and scanning abilities, the second part (TMT B) is useful to evaluate cognitive and attentional shifting and visual-spatial exploration. Finally, a third score is calculated (B-A) depending on the difference between the two performances (Tombaugh, 2004).

According to Towgood and colleagues (2009), Asperger individuals' performance on the TMT A is worse than the control group whereas Torralva and colleagues (2013) did not obtain the same result. 
Individuals with AS indeed only appear to have a slower performance in TMT B compared to NT, but when the form A score is used as a covariate for the TMT B, the AS performance no longer differs from the controls (Hill \& Bird, 2006). Therefore, a deficit in executive speed and visual-spatial exploration and not in attentional shifting could explain AS individuals' performance in TMT B (Hill \& Bird, 2006), despite the fact that Torralva and colleagues (2013) find a significant difference between AS and control on TMT B.

The majority of studies that have investigated attentional shifting ability in ASD are grounded in the Executive Dysfunction Theory (Hill, 2004; Ozonoff \& Jensen, 1999; Ozonoff, Pennington, \& Rogers, 1991; Russell, 1997). The performance of cognitive and attentional shifting, as measured by the TMT B, seems to be compromised in individuals with AS (Torralva et al., 2013).

Perceptual shifting. Within the framework of the Weak Central Coherence theory (Frith, 1989; Happé, 1999), some studies have investigated the perceptual shifting in Asperger Syndrome with the Navon task (Navon, 1977): Navon task is a paradigm used to assess local versus global visual perceptual predominance and interference. A Navon figure is usually made of a larger recognizable shape, such as a letter, composed of copies of a smaller different shape, such as smaller letters. A set of letters composed by smaller letters (for example a big "O" composed by many small " $\mathrm{H}$ ") is presented to the subject who has to respond the name either the big (global) or small (local) letter (Navon, 1977). Individuals with AS have difficulties in shifting from the local to the global elaboration of the stimuli, compared to the control group in which the opposite phenomenon is observed (Katagiri, Kasai, Kamio, \& Murohashi, 2013). The preference for a local elaboration has been recently supported by a study showing difficulties for adults with Asperger Syndrome in pre-attentively grouping stimuli into a coherent whole (Carther-Krone, Shomstein, \& Marotta, 2016). However, Gunter and colleagues (2002) failed to find differences between AS and NT individuals on a similar task.

The Embedded Figures Test (EFT) is the neuropsychological tool and a perceptual task generally used to evaluate abilities such as to distinguish and discriminate a simple shape from a complex figure (Happè, 2013; Witkin, Oltman, Raskin, \& Karp, 1971). Joliffe and Baron-Cohen (1997) did not find differences between AS, HF and controls in terms of accuracy on EFT (Witkin et al., 1971) but they noticed that both AS and HF groups were significantly faster than controls on the EET. On the other hand, Spek and colleagues, (2011) did not find strengths in AS or HF compared to controls on the same test, and Wilson and colleagues (2014) did not find significant differences on EFT between AS (and HF) and controls. Similarly, on the Gottschaldt Hidden Figures Test (Gottschaldt, 1928), a test employed to evaluate visuospatial exploration and shape discrimination, Hagberg and colleagues (2013) did not find differences between AS subgroup with and without persistent NVLD in adulthood. 
In summary, there is clear disagreement in the literature concerning attentional functions and perceptual shifting modalities in AS.

\subsection{Mnestic Abilities}

Few studies have focused on AS mnesic abilities analysing verbal memory (Torralva et al., 2013; Gunter et al., 2002), visual memory (Ambery et al., 2006; Gunter et al., 2002; Torralva et al., 2013; Towgood et al., 2009) and short-term memory (Torralva et al., 2013).

Verbal memory. The Rey Auditory Verbal Learning test (RAVLT; Rey, 1941) is commonly used to evaluate short and long term verbal memory and verbal learning through a 15 words repetition tasks (Baddeley, Kopelman, \& Wilson, 2002). No verbal memory deficits, as measured by the RAVLT, were found in adults with AS on learning and delayed recall tasks (Torralva et al., 2013). Similarly, Hagberg and colleagues (2013) failed to find differences between AS with persistent NVLD and AS without NVLD in adulthood on Claeson-Dahls Test (Claeson, Esbjönsson, Tännerus \& Wahlbin, 1998) a test commonly used to evaluate verbal learning and memory through repetition tasks of 10 unrelated words.

No significant differences were found between AS and NT controls in verbal memory tasks (Gunter et al., 2002) as measured by the Warrington Recognition Memory test (WRMT) (Warrington, 1984), a test that measures both visual and verbal memory abilities through a recognition tasks (Sweet, Demakis, Ricker, \& Millis, 2000). Ambery and colleagues (2006) did not find any impairment in AS on Verbal Index from Doors and People Battery (Baddeley, Emslie, \& Nimmo-Smith, 2006), a battery commonly used to evaluate both visual and verbal memory and recognition (Baddeley et al., 2002). The same authors did not find impairment on Wechsler Memory Scale-Revised (Wechsler, 1997) a battery composed of different subtests used to measure subcomponents of memory (verbal, visual and working memory). Towgood and colleagues in 2009 replicated Ambery's results (2006) employing Doors and People Battery.

Finally, there seems to be a dissociation between long term vs short term verbal memory: despite previously cited studies reported no long term verbal memory deficits (Ambery et al., 2006; Gunter et al., 2002; Hagberg et al., 2013; Towgood et al., 2009), Torralva and colleagues (2013) found a significant difference in short-term verbal-auditory memory between AS and controls as measured by the Digit Span Forward (Wechsler, 1997). Further studies are needed on this topic to clarify and quantify verbal memory abilities in AS population.

Visual-spatial memory. There is not agreement among authors concerning visual-spatial memory abilities in Asperger Syndrome and, in this case, it may be due to the different neuropsychological tools employed in the different studies that investigated such ability in AS population. 
The Rey complex figure Test (RCFT) (Osterrieth, 1944; Rey, 1941) is typically used and it quantifies long term visual-spatial memory (McKinlay, 2011) by copying and drawing from memory a figure. As measured by RCFT, the performance of adults with AS did not differ from NT's ones (Gunter et al., 2002; Torralva et al., 2013), and no differences have been found between AS subgroup with or without persistent NVLD in adulthood (Hagberg et al. 2013).

Conversely, Ambery and colleagues (2006) and Towgood and colleagues (2009) found that AS' performance is impaired on Doors and People Battery Visual Memory Index but not in Verbal Memory Index (Baddeley et al., 2006).

Finally, on Warrington Recognition Memory Test adults with Asperger Syndrome showed deficits in visual memory (Warrington, 1984) (Gunter et al., 2002).

Working memory. Working memory is the ability to keep in mind relevant information during the execution of a task. Torralva and colleagues (2013) concluded that AS performance is in the normal range (measured by Digit Span Backward task Wechsler, 1997). Since there is only a very limited amount of studies on working memory, further studies are needed on this topic.

In summary, there is a disagreement among authors concerning mnestic abilities in AS (particularly visual-spatial memory), and, again, it may be due to the inconsistency among the neuropsychological tests an battery employed for the assessment (see Table 2).

\subsection{Executive Functions}

The most extensive analysis of cognitive abilities in individuals with AS, ASD, and HF autism has been developed within the "Executive dysfunction theory" (Hill, 2004; Hill \& Bird, 2006), which try to explain their social and nonsocial interactions based on the inflexibility and perseveration of executive function (Lopez, Lincoln, Ozonoff, \& Lai, 2005). Some authors suggest that executive function may be even related to stereotypical behaviours (LeMonda, Holtzer, \& Goldman, 2012).

Cognitive flexibility. The Wisconsin Card Sorting Test (WCST; Berg, 1948 ) is the most common test used to evaluate the cognitive flexibility (Hill, 2004; Towgood et al., 2009). Torralva and colleagues (2013) found differences between AS and NT on modified version of WCST (Nelson, 1976). In cognitive flexibility tasks, individuals with AS make more perseverative errors (Ambery et al., 2006) and performed worse than controls (Torralva et al., 2013). However, Hill and Bird (2006) and Towgood and colleagues (2009) did not find differences between AS and control on modified version of WCST.

Finally, on a design fluency task - another diagnostic tool employed to

Neuropsychological Trends - 24/2018

http://www.ledonline.it/neuropsychologicaltrends/ 
evaluate cognitive flexibility through visual tasks-, Kleinhans, Akshoomoff, \& Delis (2005) did not find differences between subjects with High-Funtioning autism and Asperger.

Action planning and problem solving. Planning abilities are assessed employing the Tower of London task (TOL; Shallice, 1982), the Hanoi Tower (Bishop, Aamodt-Leeper, Creswell, McGurk, \& Skuse, 2001), and modified versions of these tests. Hagberg and colleagues (2013) found that a subgroup of AS individuals with persistent NVLD in adulthood (understood as NVLD= VIQ > PIQ $\geq 15$ points) scores on Tower of London test were lower (i.e. total correct score, total move score, total execution time) than both AS without NVLD and AS with a diagnosis of NVLD in childhood.

Finally, Hill and Bird (2006) found significant differences between AS and controls on Behavioural Assessment of the Dysexecutive Syndrome (BADS) (Wilson et al., 1999), particularly on problem solving (Action Program test), and planning (Zoo Map test, Six Elements test) tasks. However, Towgood and colleagues (2009) did not find differences on Zoo Map and Six Elements subtests at group level analysis between controls and AS. Nevertheless, further studies on action planning abilities in adults with AS are needed.

Inhibitory control. There are different diagnostic tools employed to measure inhibitory control and resistance to interference, such as the Stroop task (Stroop, 1935), "Go- no go tasks" (Hill, 2004) and Hayling test (Burgess \& Shallice, 1997).

Stroop is a clinical and experimental paradigm to measure interference, cognitive flexibility and inhibitory control (Hill, 2004). No difference has been found in performance on the Stroop task between AS and controls (Ambery et al., 2006; Hill \& Bird, 2006) and between HF and AS (Kleinhans et al., 2005).

"Go-no go tasks" are a type of experimental paradigm or clinical assessment tools used to measure inhibitory control, vigilance and attention, in which the subject is asked to perform some action responding to a signal or a stimulus or to inhibit an action responding to another signal/ stimulus. No difference in go-no go performance has been observed in AS (and HF) individuals as compared to the controls (Wilson et al., 2014). Whereas, on Hayling test, AS show significant difference in inhibitory response compared to controls (Hill and Bird, 2006; Towgood et al., 2009).

Verbal fluency. Verbal fluency is the ability to generate words and to access the mental lexicon. Generally, in clinical practice, two aspects of verbal fluency are measured with different neuropsychological assessment tools: semantic verbal fluency (the ability to generate words belonging to some categories) and phonemic verbal fluency (the capacity to generate words that begin with a defined letter) (Shao, Janse, Visser, \& Meyer, 2014).

Verbal fluency has been investigated in adults with Asperger Syndrome but 
contrasting results have emerged. Some studies have shown that those with AS have difficulties in phonemic verbal fluency (Ambery et al., 2006); whereas other studies obtained the opposite result (Hill \& Bird, 2006; Torralva et al., 2013; Wilson et al., 2014). Spek, Schatorje, Scholte and van Berckelaer-Onnes (2009) found differences in semantic verbal fluency between AS and NT on "profession" task; no significant differences have been found on another semantic fluency task ("animal") and in phonemic fluency tasks. Finally, Kleinhans and colleagues (2005) found no differences between AS and HF on "F-A-S" and semantic fluency tasks as well as Torralva and colleagues (2013) between AS and controls.

Decision making. Other studies have also investigated decision-making in individuals with Asperger Syndrome as measured by the Iowa Gambling Task (Bechara, Damasio, Damasio, \& Anderson, 1994).

Adults with AS showed a proportion of suitable choices that were comparable to the ones made by the NT control group. However, the two groups used different strategies when choosing cards despite comparable performance; the AS group had a peculiar pattern of choices as they shifted decks more frequently (Torralva et al., 2013).

Cognitive Estimation. Cognitive estimation is a neuropsychological skill referred to the ability to adequately and realistically estimate distances, durations and weights; in certain neurological diseases, this skill is impaired (Taylor and O'Carrol, 1995).

Hill and Bird (2006) found significant differences between AS and control on a cognitive estimation task (Temporal Judgment test) assessed using BADS, whereas Towgood and colleagues (2009), using the Cognitive Estimation Test (Shallice \& Evans, 1978), did not find differences between adults with AS and controls at group level analysis.

Summarizing, results about executive functions in Asperger Syndrome are divergent: there is inconsistency between studies about neuropsychological instruments employed but further studies are needed.

\subsection{Praxis abilities}

Many studies have evaluated praxis abilities in autistic children and found an impairment as compared to healthy control groups (Ham et al., 2011; Ham, Corley, Rajendran, Carletta, \& Swanson, 2008; MacNeil \& Mostofsky, 2012), which could be related to social and communicative deficits (Dziuk et al., 2007). However, the evaluations of praxis abilities in adults with AS are missing. These assessments should be included in future neuropsychological evaluations of adults with AS considering that, clinically, AS includes motor clumsiness since early childhood 


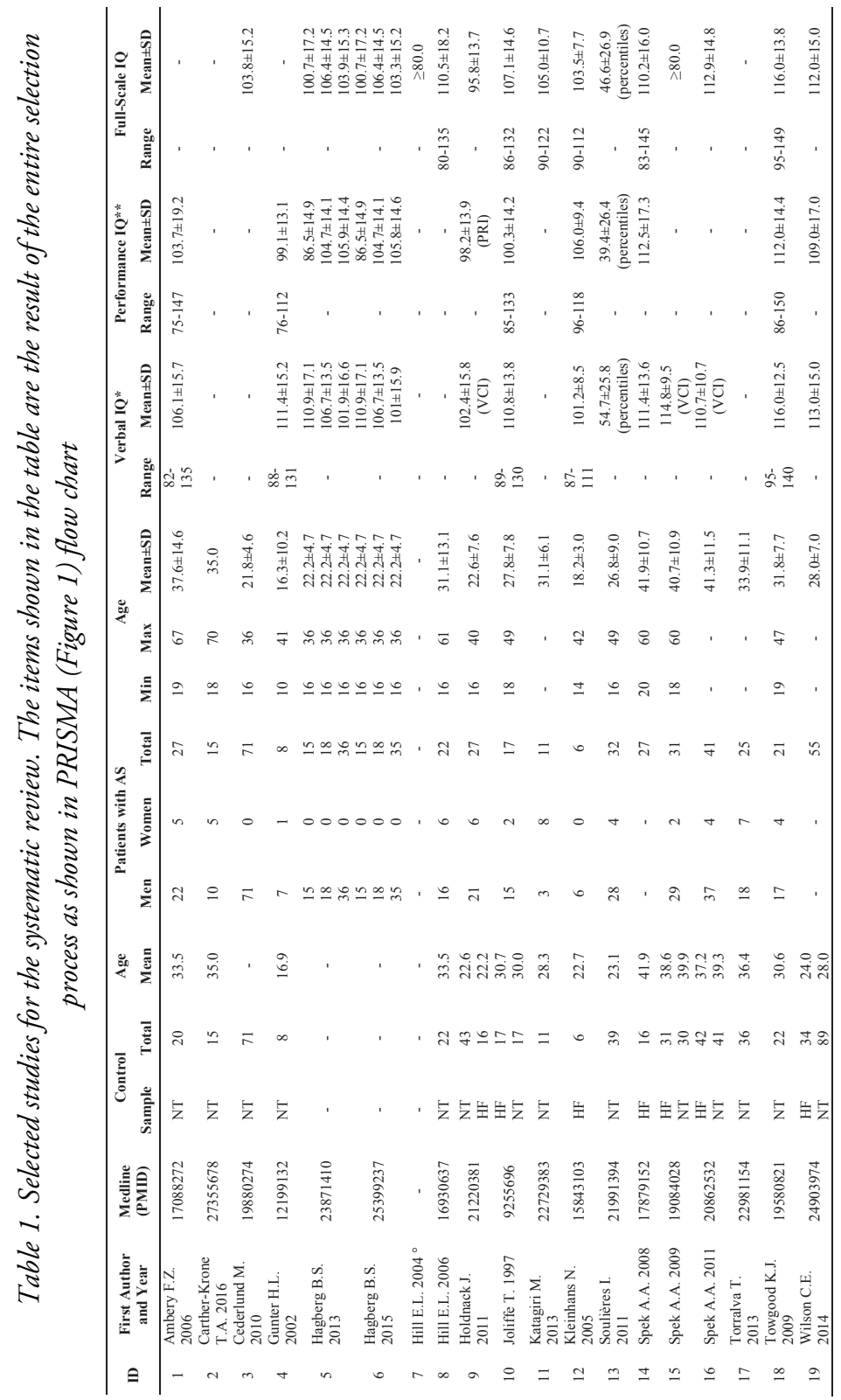

Neuropsychological Trends - 24/2018

http://www.ledonline.it/neuropsychologicaltrends/ 


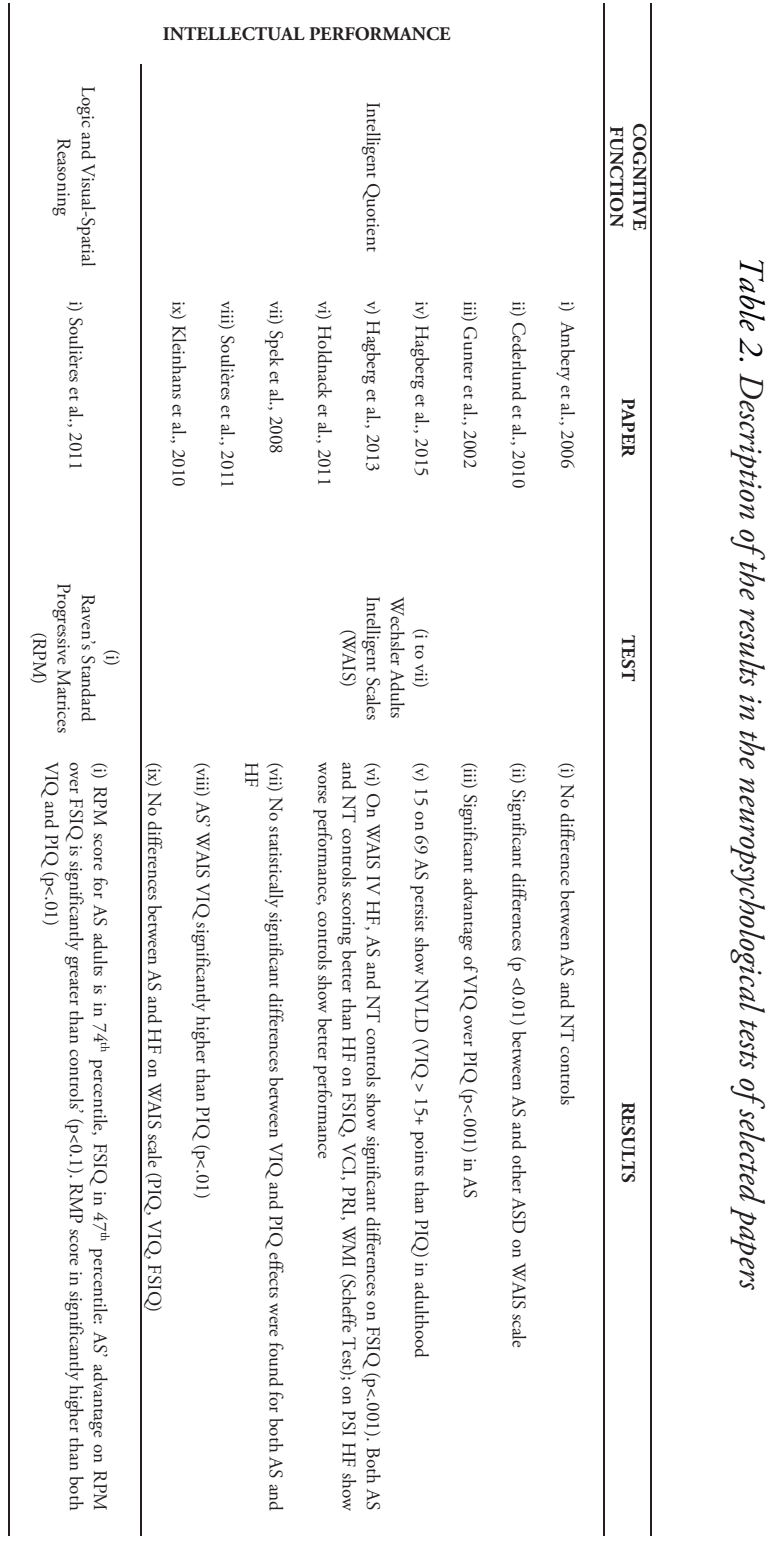

Neuropsychological Trends - 24/2018

http://www.ledonline.it/neuropsychologicaltrends/ 


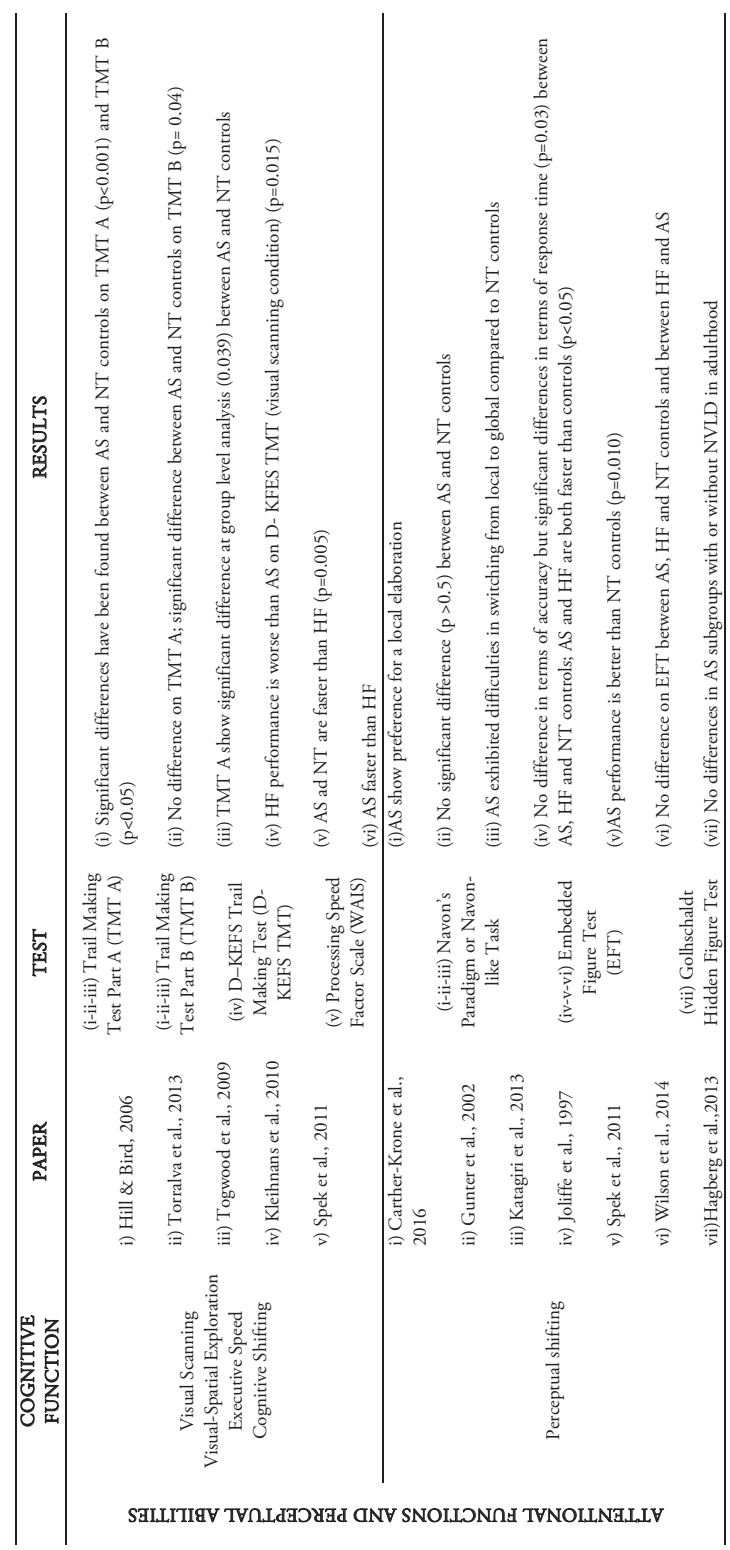

Neuropsychological Trends - 24/2018

http://www.ledonline.it/neuropsychologicaltrends/ 


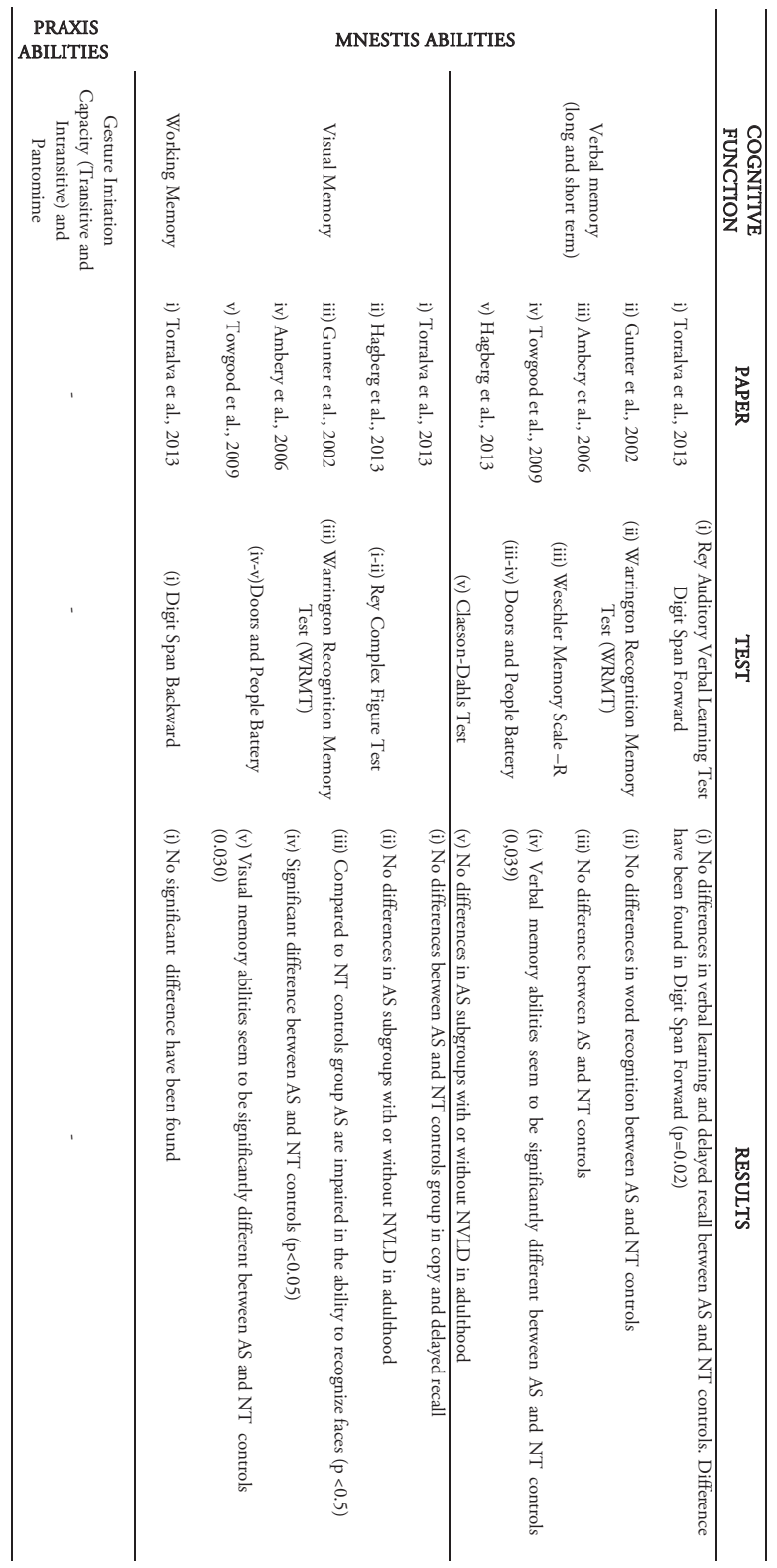

Neuropsychological Trends - 24/2018

http://www.ledonline.it/neuropsychologicaltrends/ 


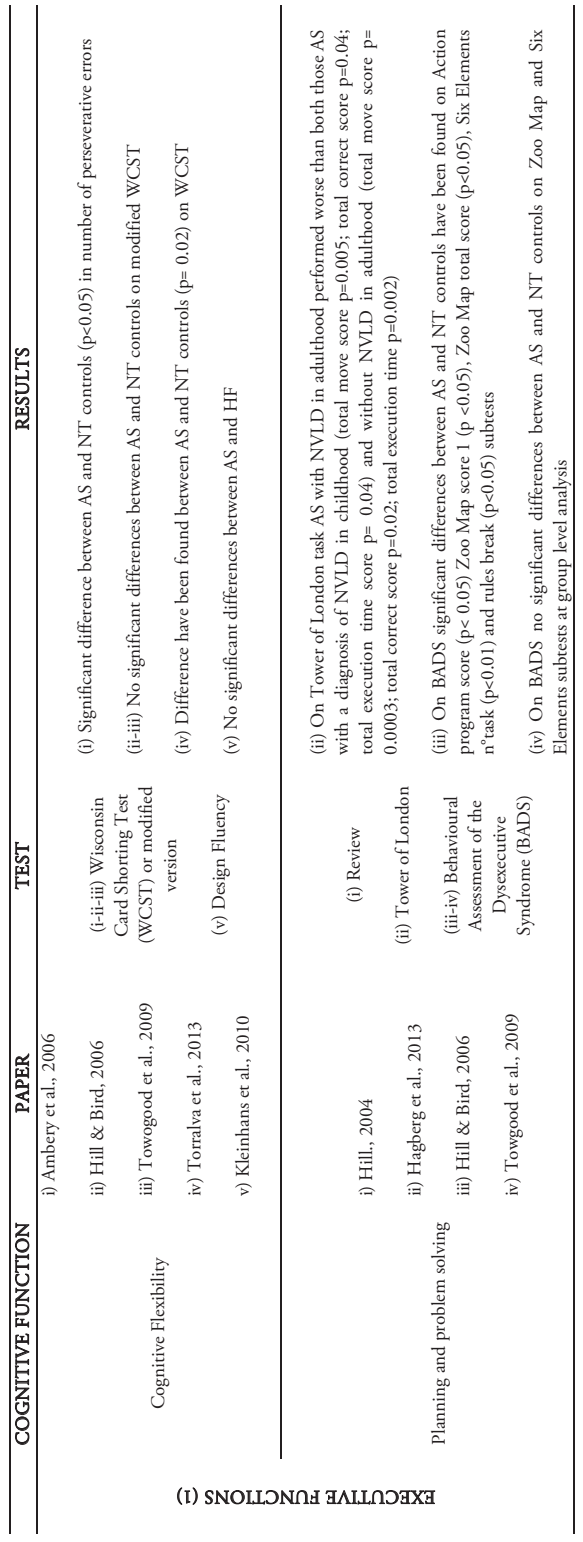

Neuropsychological Trends - 24/2018

http://www.ledonline.it/neuropsychologicaltrends/ 


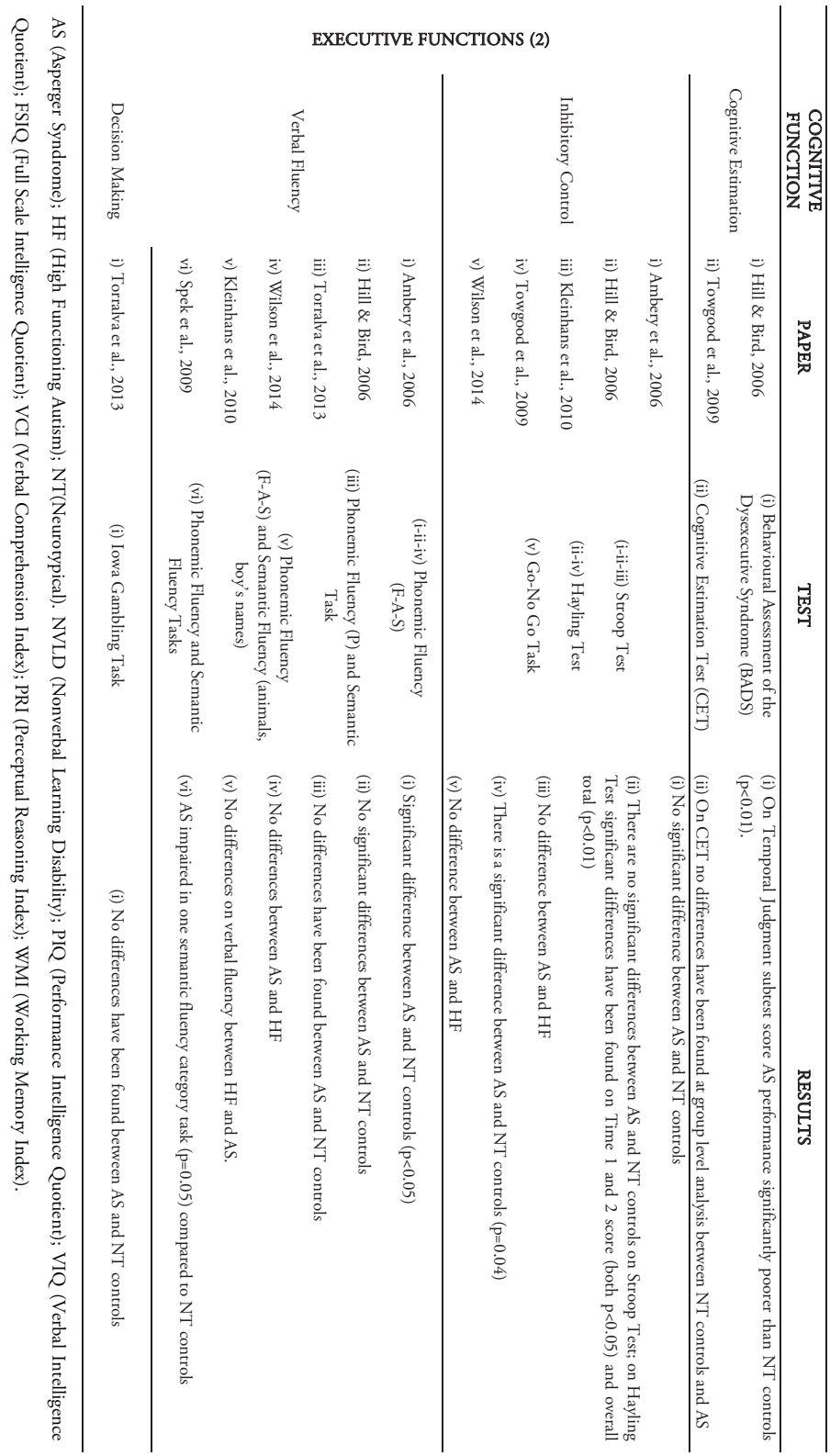

Neuropsychological Trends - 24/2018

http://www.ledonline.it/neuropsychologicaltrends/ 


\section{DISCUSSION}

Only a limited number of studies have investigated the neuropsychological profile of Asperger Syndrome in adults (Ambery et al., 2006; Wilson et al., 2014) (Table 1 and Table 2). Therefore, even if to date there are not enough data to clearly identify a specific neuropsychological profile for individuals with Asperger Syndrome, we can propose some neuropsychological markers that could help clinicians to evaluate AS in adulthood (see Table 3).

First, individuals with Asperger Syndrome have intellectual abilities in the normal range (Holdnack et al., 2011) but obtain better scores on Full Scale IQ than other individuals with ASD (Cederlund et al., 2010), and higher IQ than individuals with HF. Even if there is no complete agreement, individuals with AS generally present strength in verbal intelligence and weakness in visual-spatial intelligence (Cederlund et al., 2010; Gunter et al., 2002; Hagberg et al., 2015; Hagberg et al., 2013; Holdnack et al., 2011; Keinhans et al., 2005; Soulières et al., 2011; Spek et al., 2008). Concerning with attentional abilities, some authors emphasize difficulties in executive speed, visual-spatial exploration and attentional shifting (Hill \& Bird, 2006; Torralva et al., 2013; Towgood et al., 2009). There is also no agreement about perceptual shifting modalities in AS (Carther- Krone et al., 2016; Joliffe \& Baron-Cohen, 1997; Spek et al., 2011; Gunter et al., 2002; Katagiri et al., 2013; Wilson et al., 2014).

Concerning mnesic abilities, even if some studies have found that long term verbal memory performance in individuals with AS is comparable to controls (Ambery et al., 2006; Gunter et al., 2002; Hagberg et al., 2013) as well as working memory abilities (Torralva et al., 2013), short term verbal and auditory memory (Torralva et al., 2013) are weaker than controls.

Individuals with AS have not shown deficits in coping and remembering a figure (Hagberg et al, 2015; Torralva et al., 2013), but they have been shown to struggle with tasks of image recognition (Ambery et al., 2006; Gunter et al., 2002; Towgood et al., 2009).

Concerning with executive functions, despite the results about cognitive flexibility are divergent (Ambery et al., 2006; Hill \& Bird, 2006; Torralva et al., 2013; Towgood et al., 2009; Kleinhans et al., 2005), the ability to resist and overcome interference and inhibitory control is shown to be a strength of individuals with Asperger Syndrome (Hill, 2004; Hill \& Bird, 2006; Towgood et al., 2009; Kleinhans et al., 2005; Wilson et al., 2014). Regarding action planning and problem solving, individuals with AS show impairment (Hagberg et al., 2013; Hill, 2004; Hill and Bird, 2006). Concerning both phonemic and semantic verbal fluency, there is disagreement regarding the presence of deficits (Ambery et al., 2006; Hill \& Bird, 2006; Spek et al., 2009; Kleinhans et al., 2005; Torralva et al., 2013; Wilson et al., 2014). Decision-making is in the normal range, but individuals with AS show specific 
decision-making behaviour (Torralva et al., 2013).

Finally, studies concerning praxis abilities in adult AS are missing.

It is important to mention that these results gathered from 30 years of literature have a limited generalizability, since diagnostic criteria have changed over time. Moreover, limited sample sizes, including mainly male participants, along with the heterogeneity in the experimental and control groups could have led to such variable findings (see Table 1). The incongruence in the literature clearly demonstrates the need for experimental samples that would account for such distinction among individuals with diagnosis of AS and HF. Therefore, further research studies are needed. This is not only a limitation of our work but also an ultimate call for the development of a standardized neuropsychological battery that is able to characterize AS neuropsychological profile.

In the clinical context, a neuropsychological assessment for AS can be precious as it can constitute an additional tool to support diagnosis helping in discriminating AS from other ASD, neurodevelopmental or psychotic disorders, as well as in tailoring the necessary rehabilitative treatment and, consequently, to provide better prognoses.

In light of these considerations, the need of a deeper investigation of the neuropsychological profile of individual with AS stands clear.

Table 3. Neuropsychological aspects of Asperger Syndrome in adults: a possible brief guide for clinicians

\begin{tabular}{l}
\hline Intellectual Performance \\
\hline Intelligence Quotient in Normal Range \\
Asperger's Intelligence Quotient higher than other Autism Spectrum conditions \\
Verbal Intelligence Quotient $>$ Performance Intelligence Quotient \\
\hline Attentional Functions \\
\hline Difficulties in executive speed \\
visual-spatial exploration \\
attentional shifting \\
Adults with Asperger Syndrome are faster than High Functioning ones \\
\hline Memory \\
\hline Long term verbal memory in normal range \\
Difficulties in short term verbal memory \\
Difficulties in image recognition \\
Working memory in normal range \\
\hline Executive Functions \\
\hline Good inhibitory control \\
Impairment in planning \\
Decision making in normal range
\end{tabular}

Neuropsychological Trends - 24/2018

http://www.ledonline.it/neuropsychologicaltrends/ 


\section{REFERENCES}

Ambery, F. Z., Russell, A. J., Perry, K., Morris, R., \& Murphy, D. G. (2006). Neuropsychological functioning in adults with Asperger syndrome. Autism, 10(6), 551-564.

American Psychiatric Association. (1980). Diagnostic and Statistical Manual of Mental Disorders (3th ed.). Washington, DC: Author.

American Psychiatric Association. (1994). Diagnostic and Statistical Manual of Mental Disorders (4th ed.). Washington, DC: Author.

American Psychiatric Association. (2013). Diagnostic and Statistical Manual of Mental Disorders (5th ed.). Arlington, VA: Author.

Asperger, H. (1944). Die 'Autistischen Psychopathen'im Kindesalter. Archiv fur Psychiatrie und Nervenkrankheiten, 117, 76-136.

Baddeley, A. D., Emslie, H., \& Nimmo-Smith, I. (2006). Doors and people: a test of visual and verbal recall and recognition: Harcourt Assessment.

Baddeley, A. D., Kopelman, M. D., \& Wilson, B. A. (2002). The handbook of memory disorders. New York, NY: John Wiley \& Sons.

Barahona-Correa, J. B., \& Filipe, C. N. (2015). A Concise History of Asperger Syndrome: The Short Reign of a Troublesome Diagnosis. Frontiers in Psychology, 6, 2024.

Baron-Cohen, S. (2002). The extreme male brain theory of autism. Trends in Cognitive Sciences, 6(6), 248-254.

Baron-Cohen, S., Leslie, A. M., \& Frith, U. (1985). Does the autistic child have a "theory of mind"? Cognition, 21(1), 37-46.

Baron-Cohen, S., Lombardo, M. V., Auyeung, B., Ashwin, E., Chakrabarti, B., \& Knickmeyer, R. (2011). Why are autism spectrum conditions more prevalent in males? PLoS Biology, 9(6), e1001081.

Baron-Cohen, S., Ring, H., Moriarty, J., Schmitz, B., Costa, D., \& Ell, P. (1994). Recognition of mental state terms. Clinical findings in children with autism and a functional neuroimaging study of normal adults. The British Journal of Psychiatry, 165(5), 640-649.

Baron-Cohen, S., \& Wheelwright, S. (2004). The empathy quotient: an investigation of adults with Asperger syndrome or high functioning autism, and normal sex differences. Journal of Autism and Developmental Disorders, 34(2), 163-175.

Baron-Cohen, S., Wheelwright, S., Robinson, J., \& Woodbury-Smith, M. (2005). The adult Asperger assessment (AAA): a diagnostic method. Journal of Autism and Developmental Disorders, 35(6), 807. 
Baron-Cohen, S., Wheelwright, S., Skinner, R., Martin, J., \& Clubley, E. (2001). The autism-spectrum quotient (AQ): Evidence from asperger syndrome/highfunctioning autism, malesand females, scientists and mathematicians. Journal of Autism and Developmental Disorders, 31(1), 5-17.

Bechara, A., Damasio, A. R., Damasio, H., \& Anderson, S. W. (1994). Insensitivity to future consequences following damage to human prefrontal cortex. Cognition, 50(1), 7-15.

Berg, E. A. (1948). A simple objective technique for measuring flexibility in thinking. The Journal of general psychology, 39(1), 15-22.

Biamino, E., Di Gregorio, E., Belligni, E. F., Keller, R., Riberi, E., Gandione, M., . . . Brusco, A. (2016). A novel 3q29 deletion associated with autism, intellectual disability, psychiatric disorders, and obesity. American Journal of Medical Genetics Part B: Neuropsychiatric Genetics, 171(2), 290-299.

Bishop, D., Aamodt-Leeper, G., Creswell, C., McGurk, R., \& Skuse, D. (2001). Individual differences in cognitive planning on the Tower of Hanoi task: Neuropsychological maturity or measurement error? The Journal of Child Psychology and Psychiatry and Allied Disciplines, 42(4), 551-556.

Bleuler, E. (1911). Dementia praecox, oder Gruppe der Schizophrenien. Leipzig: Deuticke.

Bodner, K. E., Williams, D. L., Engelhardt, C. R., \& Minshew, N. J. (2014). A comparison of measures for assessing the level and nature of intelligence in verbal children and adults with autism spectrum disorder. Research in Autism Spectrum Disorders, 8(11), 1434-1442.

Boso, M., Emanuele, E., Prestori, F., Politi, P., Barale, F., \& D'Angelo, E. (2010). Autism and genius: is there a link? The involvement of central brain loops and hypotheses for functional testing. Functional Neurology, 25(1), 15-20.

Burgess, P. W., \& Shallice, T. (1997). The Hayling and Brixton tests. Bury St. Edmonds, UK: Thames Valley Test Company.

Canavan, A. G., Dunn, G., \& Mcmillan, T. M. (1986). Principal components of the WAIS-R. British Journal of Clinical Psychology, 25, 81-5.

Carther-Krone, T. A., Shomstein, S., \& Marotta, J. J. (2016). Looking without Perceiving: Impaired Preattentive Perceptual Grouping in Autism Spectrum Disorder. PLoS One, 11(6), e0158566.

Cauda, F., Costa, T., Palermo, S., D'Agata, F., Diano, M., Bianco, F., Keller, R. (2014). Concordance of white matter and gray matter abnormalities in autism spectrum disorders: A voxel-based meta-analysis study. Human Brain Mapping, 35(5), 2073-2098. 
Cauda, F., Geda, E., Sacco, K., D'Agata, F., Duca, S., Geminiani, G., \& Keller, R. (2011). Grey matter abnormality in autism spectrum disorder: an activation likelihood estimation meta-analysis study. Journal of Neurology, Neurosurgery and Psychiatry, 82(12), 1304-1313.

Cederlund, M., Hagberg, B., \& Gillberg, C. (2010). Asperger syndrome in adolescent and young adult males. Interview, self-and parent assessment of social, emotional, and cognitive problems. Research in developmental disabilities, 31(2), 287-298.

Claeson, L. E., Esbjönsson, E., Tännérus, B. M., Wahlbin, M., (1998). Claeson-Dabls Test för Inläning Och Minne-Reviderad Version. Psykologiförlaget: $\mathrm{AB}$ Halmstad.

Di Gregorio, E., Riberi, E., Belligni, E. F., Biamino, E., Spielmann, M., Ala, U., . . Brusco, A. (2017). Copy number variants analysis in a cohort of isolated and syndromic developmental delay/intellectual disability reveals novel genomic disorders, position effects and candidate disease genes. Clinical Genetics, 92(4), 415-422.

Dziuk, M., Larson, J., Apostu, A., Mahone, E., Denckla, M., \& Mostofsky, S. (2007). Dyspraxia in autism: association with motor, social, and communicative deficits. Developmental Medicine \& Child Neurology, 49(10), 734-739.

Fine J.G., Semrud-Clikeman M., Bledsoe J.C., \& Musielak K.A., (2013) A critical review of the literature on NLD as a developmental disorder, Child Neuropsychology, 19 (2), 190-223

Fonagy, P., \& Target, M. (1997). Attachment and reflective function: Their role in selforganization. Development and psychopathology, 9(4), 679-700.

Frith, C. D., \& Frith, U. (1999). Interacting minds--a biological basis. Science, 286(5445), $1692-1695$.

Frith, U. (1989). Autism: Explaining the enigma (Vol. 1989): Wiley Online Library.

Frith, U. (1991). Asperger and his syndrome. Autism and Asperger syndrome, 14, 1-36.

Gilliam, J. E. (2001). Gilliam Asperger's Disorder Scale. Austin, TX: GADS.

Gottschaldt, K., (1928). Uber den Einfluss der Erfahrung auf die Wahrnehmung von Figuren. Psychologische Forschung, 8, 18-317

Gunter, H. L., Ghaziuddin, M., \& Ellis, H. D. (2002). Asperger syndrome: Tests of right hemisphere functioning and interhemispheric communication. Journal of Autism and Developmental Disorders, 32(4), 263-281.

Hadwin, J., Baron-Cohen, S., Howlin, P., \& Hill, K. (1997). Does teaching theory of mind have an effect on the ability to develop conversation in children with autism? Journal of Autism and Developmental Disorders, 27(5), 519-537. 
Hagberg, B., Billstedt, E., Nydén, A., \& Gillberg, C. (2015). Asperger syndrome and nonverbal learning difficulties in adult males: self-and parent-reported autism, attention and executive problems. European child \& adolescent psychiatry, 24(8), 969-977.

Hagberg, B. S., Nydén, A., Cederlund, M., \& Gillberg, C. (2013). Asperger syndrome and "non-verbal learning problems" in a longitudinal perspective: Neuropsychological and social adaptive outcome in early adult life. Psychiatry research, 210(2), 553-558.

Ham, H. S., Bartolo, A., Corley, M., Rajendran, G., Szabo, A., \& Swanson, S. (2011). Exploring the relationship between gestural recognition and imitation: Evidence of dyspraxia in autism spectrum disorders. Journal of Autism and Developmental Disorders, 41(1), 1-12.

Ham, H. S., Corley, M., Rajendran, G., Carletta, J., \& Swanson, S. (2008). Brief report: Imitation of meaningless gestures in individuals with Asperger syndrome and highfunctioning autism. Journal of Autism and Developmental Disorders, 38(3), 569-573.

Happé, F. (1999). Autism: cognitive deficit or cognitive style? Trends in Cognitive Sciences, 3(6), 216-222.

Happé, F. (2013). Embedded Figures Test (EFT). In F. R. Volkmar (Ed.), Encyclopedia of Autism Spectrum Disorders (pp. 1077-1078). New York, NY: Springer US.

Hayashi, M., Kato, M., Igarashi, K., \& Kashima, H. (2008). Superior fluid intelligence in children with Asperger's disorder. Brain and cognition, 66(3), 306-310.

Hill, E. L. (2004). Evaluating the theory of executive dysfunction in autism. Developmental review, 24(2), 189-233.

Hill, E. L., \& Bird, C. M. (2006). Executive processes in Asperger syndrome: Patterns of performance in a multiple case series. Neuropsychologia, 44(14), 2822-2835.

Holdnack, J., Goldstein, G., \& Drozdick, L. (2011). Social perception and WAIS-IV performance in adolescents and adults diagnosed with Asperger's syndrome and autism. Assessment, 18(2), 192-200.

Holroyd, S., \& Baron-Cohen, S. (1993). Brief report: How far can people with autism go in developing a theory of mind? Journal of Autism and Developmental Disorders, 23(2), 379-385.

Jolliffe, T., \& Baron-Cohen, S. (1997). Are people with autism and Asperger syndrome faster than normal on the Embedded Figures Test? Journal of Child Psychology and Psychiatry, 38(5), 527-534. 
Kanner, L. (1943). Autistic disturbances of affective contact. Nervous Child, 2, 217-250.

Katagiri, M., Kasai, T., Kamio, Y., \& Murohashi, H. (2013). Individuals with Asperger's disorder exhibit difficulty in switching attention from a local level to a global level. Journal of Autism and Developmental Disorders, 43(2), 395-403.

Keller R, Piedimonte A, Bianco F, Bari S, Cauda F. (2016). Diagnostic Characteristics of Psychosis and Autism Spectrum Disorder in Adolescence and Adulthood. A Case Series. Autism Open Access, 6, 159.

Keller, R., Bari, S., Aresi, A., Notaro, L., Bianco, F., \& Pirfo, E. (2015). Diagnosing autism spectrum disorders in adulthood. Journal of Psychopathology, 21, 13-18.

Keller, R., Bugiani, S., Fantin, P., \& Pirfo, E. (2011). Mirror neurons and autism. Journal of Psychopathology, 17, 404-412.

Kleinhans, N., Akshoomoff, N., \& Delis, D. C. (2005). Executive functions in autism and Asperger's disorder: flexibility, fluency, and inhibition. Developmental neuropsychology, 27(3), 379-401.

Klin, A., Volkmar, F. R., Sparrow, S. S., Cicchetti, D., \& Rourke, B. P. (1995). Validity and neuropsychological characterization of Asperger syndrome: Convergence with nonverbal learning disabilities syndrome. Journal of Child Psychology and Psychiatry, 36(7), 1127-1140.

Krystal, J. H., \& State, M. W. (2014). Psychiatric disorders: diagnosis to therapy. Cell, 157(1), 201-214.

Lai, M. C., \& Baron-Cohen, S. (2015). Identifying the lost generation of adults with autism spectrum conditions. Lancet Psychiatry, 2(11), 1013-1027.

LeMonda, B. C., Holtzer, R., \& Goldman, S. (2012). Relationship between executive functions and motor stereotypies in children with autistic disorder. Research in Autism Spectrum Disorders, 6(3), 1099-1106.

Liberati, A., Altman, D. G., Tetzlaff, J., Mulrow, C., Gotzsche, P. C., Ioannidis, J. P., . . . Moher, D. (2009). The PRISMA statement for reporting systematic reviews and meta-analyses of studies that evaluate health care interventions: explanation and elaboration. Journal of Clinical Epidemiology, 62(10), 1-34.

Lopez, B. R., Lincoln, A. J., Ozonoff, S., \& Lai, Z. (2005). Examining the relationship between executive functions and restricted, repetitive symptoms of autistic disorder. Journal of Autism and Developmental Disorders, 35(4), 445-460.

Lord, C., Rutter, M., DiLavore, P. C., \& Risi, S. (2008). Autism diagnostic observation schedule: ADOS manual. Los Angeles, CA: Western Psychological Services.

Luciano, C., Keller, R., Politi, P., Aguglia, E., Magnano, F., Burti, L...Berardi, D (2014). Misdiagnosis of high function autism spectrum disorders in adults: an Italian case series. Autism Open Access, 4(131), 2. 
MacNeil, L. K., \& Mostofsky, S. H. (2012). Specificity of dyspraxia in children with autism. Neuropsychology, 26(2), 165.

McKinlay, A. (2011). Rey Complex Figure Test Encyclopedia of Child Behavior and Development (pp. 1264-1265). Boston, MA: Springer US.

Moher, D., Liberati, A., Tetzlaff, J., \& Altman, D. G. (2009). Preferred reporting items for systematic reviews and meta-analyses: the PRISMA statement. Journal of Clinical Epidemiology, 62(10), 1006-1012.

Morris, R. G., Rowe, A., Fox, N., Feigenbaum, J., Miotto, E., \& Howlin, P. (1999). Spatial working memory in Asperger's syndrome and in patients with focal frontal and temporal lobe lesions. Brain and cognition, 41(1), 9-26.

Moseley, R. L., Correia, M. M., Baron-Cohen, S., Shtyrov, Y., Pulvermüller, F., \& Mohr, B. (2016). Reduced volume of the arcuate fasciculus in adults with highfunctioning autism spectrum conditions. Frontiers in human neuroscience, 10, 214.

Mottron, L., Bouvet, L., Bonnel, A., Samson, F., Burack, J. A., Dawson, M., \& Heaton, P. (2013). Veridical mapping in the development of exceptional autistic abilities. Neuroscience \& Biobehavioural Reviews, 37(2), 209-228.

Mottron, L., Dawson, M., Soulieres, I., Hubert, B., \& Burack, J. (2006). Enhanced perceptual functioning in autism: an update, and eight principles of autistic perception. Journal of Autism and Developmental Disorders, 36(1), 27-43.

Myklebust, H. R. (1975). Progress in learning disabilities (Vol. 3). New York, NY: Grune and Stratton.

Navon, D. (1977). Forest before trees: The precedence of global features in visual perception. Cognitive psychology, 9(3), 353-383.

Nelson, H. E. (1976). A modified card sorting test sensitive to frontal lobe defects. Cortex, 12(4), 313-324.

Noterdaeme, M., Wriedt, E., \& Höhne, C. (2010). Asperger's syndrome and highfunctioning autism: Language, motor and cognitive profiles. European child \& adolescent psychiatry, 19(6), 475-481.

Osterrieth, P. (1944). Test of copying a complex figures: contribution to the study of perception and memory. Archives of Psychology, 20, 206-356. 
Ozonoff, S., \& Jensen, J. (1999). Brief report: Specific executive function profiles in three neurodevelopmental disorders. Journal of Autism and Developmental Disorders, 29(2), 171-177.

Ozonoff, S., Pennington, B. F., \& Rogers, S. J. (1991). Executive function deficits in high-functioning autistic individuals: relationship to theory of mind. Journal of Autism and Developmental Disorders, 32(7), 1081-1105.

Premack, D., \& Woodruff, G. (1978). Does the chimpanzee have a theory of mind? Behavioral and brain sciences, 1(4), 515-526.

Raven, J. C. (1941). Standardization of progressive matrices, 1938. Psychology and Psychotherapy: Theory, Research and Practice, 19(1), 137-150.

Reitan, R. M. (1958). Validity of the Trail Making Test as an indicator of organic brain damage. Perceptual and motor skills, 8(3), 271-276.

Rey, A. (1941). L'examen psychologique dans les cas d'encéphalopathie traumatique.(Les problems.). Archives de psychologie.

Ritvo, R. A., Ritvo, E. R., Guthrie, D., Ritvo, M. J., Hufnagel, D. H., McMahon, W., . . . Attwood, T. (2011). The Ritvo Autism Asperger Diagnostic Scale-Revised (RAADS-R): a scale to assist the diagnosis of autism spectrum disorder in adults: an international validation study. Journal of Autism and Developmental Disorders, 41(8), 1076-1089.

Rizzolatti, G., \& Craighero, L. (2004). The mirror-neuron system. Annual Review of Neuroscience, 27, 169-192.

Rizzolatti, G., \& Fabbri-Destro, M. (2010). Mirror neurons: from discovery to autism. Experimental Brain Research, 200(3-4), 223-237.

Rizzolatti, G., Fadiga, L., Gallese, V., \& Fogassi, L. (1996). Premotor cortex and the recognition of motor actions. Brain Research. Cognitive Brain Research, 3(2), 131-141.

Rourke, B. P. (1987). Syndrome of nonverbal learning disabilities: The final common pathway of white-matter disease/dysfunction? The Clinical Neuropsychologist, 1(3), 209-234.

Rourke, B. P. (1988). The syndrome of nonverbal learning disabilities: Developmental manifestations in neurological disease, disorder, and dysfunction. The Clinical Neuropsychologist, 2(4), 293-330.

Rourke, B. P. (1995). Syndrome of nonverbal learning disabilities: Neurodevelopmental manifestations. New York, NY: Guilford Press.

Russell, J. E. (1997). Autism as an executive disorder. New York, NY: Oxford University Press. 
Rutter, M., Le Couteur, A., \& Lord, C. (2003). Autism diagnostic interview-revised. Los Angeles, CA: Western Psychological Services, 29, 30.

Saffin, J. M., \& Tohid, H. (2016). Walk like me, talk like me. The connection between mirror neurons and autism spectrum disorder. Neurosciences (Riyadh), 21(2), 108-119.

Shallice, T. (1982). Specific impairments of planning. Philosophical Transactions of the Royal Society of London B: Biological Sciences, 298(1089), 199-209.

Shallice, T. \& Evans, M. (1978). The involvement of the frontal lobes in cognitive estimation. Cortex, 14, 294-303.

Shao, Z., Janse, E., Visser, K., \& Meyer, A. S. (2014). What do verbal fluency tasks measure? Predictors of verbal fluency performance in older adults. Frontiers in Psychology, 5.

Soulières, I., Dawson, M., Gernsbacher, M. A., \& Mottron, L. (2011). The level and nature of autistic intelligence II: what about Asperger syndrome? PloS one, 6(9), e25372.

Spek, A. A., Schatorje, T., Scholte, E., \& van Berckelaer-Onnes, I. (2009). Verbal fluency in adults with high functioning autism or Asperger syndrome. Neuropsychologia, 47(3), 652-656.

Spek, A. A., Scholte, E. M., \& van Berckelaer-Onnes, I. A. (2008). Brief report: The use of WAIS-III in adults with HFA and Asperger syndrome. Journal of Autism and Developmental Disorders, 38(4), 782-787.

Spek, A. A., Scholte, E. M., \& van Berckelaer-Onnes, I. A. (2011). Local information processing in adults with high functioning autism and asperger syndrome: the usefulness of neuropsychological tests and self-reports. Journal of Autism and Developmental Disorders, 41(7), 859-869.

Stroop, J. R. (1935). Studies of interference in serial verbal reactions. Journal of Experimental Psychology, 18(6), 643-662.

Sweet, J. J., Demakis, G. J., Ricker, J. H., \& Millis, S. R. (2000). Diagnostic efficiency and material specificity of the Warrington Recognition Memory Test: A collaborative multisite investigation. Archives of Clinical Neuropsychology, 15(4), 301-309.

Taylor, R. \& O'Carroll, R. (1995), Cognitive estimation in neurological disorders. British Journal of Clinical Psychology, 34, 223-228.

Tombaugh, T. N. (2004). Trail Making Test A and B: normative data stratified by age and education. Archives of Clinical Neuropsychology, 19(2), 203-214.

Torralva, T., Gleichgerrcht, E., Roca, M., Ibanez, A., Marenco, V., Rattazzi, A., \& Manes, F. (2013). Impaired theory of mind but intact decision-making in Asperger syndrome: implications for the relationship between these cognitive domains. Psychiatry Research, 205(3), 282-284. 
Towgood, K. J., Meuwese, J. D., Gilbert, S. J., Turner, M. S., \& Burgess, P. W. (2009). Advantages of the multiple case series approach to the study of cognitive deficits in autism spectrum disorder. Neuropsychologia, 47(13), 2981-2988.

Warrington, E. K. (1984). Recognition Memory Test: Rmt.(Words). Test Booklet 1. NFERNelson Publishing Company.

Wechsler, D. (1981) Manual for the Wechsler Adult Intelligence Scale—Revised. New York, NY: Psychological Corporation.

Wechsler, D. (1997). WAIS-III: Wechsler adult intelligence scale. San Antonio, TX: Psychological Corporation.

Wechsler, D. (1999). Wechsler Abbreviated Scale of Intelligence. San Antonio, TX: Psychological Corporation.

Wechsler, D. (2008). Wechsler adult intelligence scale-Fourth Edition (WAIS-IV). San Antonio, TX: NCS Pearson.

Williams, D. L., Goldstein, G., Kojkowski, N., \& Minshew, N. J. (2008). Do individuals with high functioning autism have the IQ profile associated with nonverbal learning disability? Research in Autism Spectrum Disorders, 2(2), 353-361.

Wilson, C. E., Happé, F., Wheelwright, S. J., Ecker, C., Lombardo, M. V., Johnston, P., . . . Lai, M. C. (2014). The neuropsychology of male adults with high-functioning autism or asperger syndrome. Autism Research, 7(5), 568-581.

Wing, L. (1981). Asperger's syndrome: a clinical account. Psychological Medicine, 11(1), $115-129$.

Witkin, H. A., Oltman, P. K., Raskin, E., \& Karp, S. A. (1971). A manual for the embedded figures test. Palo Alto, CA: Consulting Psychologists Press. 
